\title{
PROBLEMAS PALEOGRÁFICOS \\ Y DIPLOMÁTICOS EN LA \\ DOCUMENTACIÓN DEL SIGLO X \\ REFERENTE A LOS ORÍGENES \\ DE UN LINAJE
}

\author{
Blanca Garí
}

Todo parece indicar que los orígenes del linaje deben buscarse en las transformaciones que acaecieron en el suelo europeo en la segunda mitad del siglo X. El historiador preocupado por estas cuestiones sabe que en la documentación de esa época, escasa y llena de dificultades, se encuentran reflejados esos cambios, esa nueva forma de organizar el territorio, esa novedosa manera de concebir la estructura familiar. Por ello, al intentar seguir los pasos concretos de la formación de un determinado linaje, el análisis cuidadoso y matizado de esos valiosos pergaminos se torna una necesidad de primer orden. Su clarificación paleográfica, diplomática y de contenidos históricos es de gran importancia, pues de ella depende en parte la posibilidad de perfilar cronológicamente la formación del linaje.

Es un trabajo en su mayor parte por hacer. Personalmente, quiero presentar aquí tan sólo un ejemplo que marca, a mi entender, las pautas de algunas cuestiones que hay que tener en cuenta. Se trata 
de la documentación del siglo $\mathrm{x}$ referente al linaje de Castellvell ${ }^{1}$, únicamente seis pergaminos de los que, sin embargo, se puede sustraer una experiencia enriquecedora. Para ello intentaré confrontar el análisis morfológico con los problemas de contenido que estos documentos suscitan; la documentación no proviene toda del mismo archivo, ni plantea toda ella idénticas dificultades. Muy al contrario, las cuestiones que hay que dilucidar son de diversa índole; por tanto, expondré y analizaré separadamente cada documento. Por último, situándome en el campo de la crítica textual ${ }^{2}$, intentaré establecer algunas hipótesis.

\section{Primer documento}

Archivo de la corona de Aragón, Cancillería, pergaminos Ramón Berenguer III, núm. 134 (núm. 1): se trata de la venta que Salomó, su esposa Vigilia, y sus hijos Esteve y Oriol, hacen a Sendred de la mitad de dos molinos que poseían en el término de Castellvell junto al Anoia, 9 de noviembre del 938.

Pergamino de $147 \times 360 \mathrm{~mm}$. Forma rectangular. Bien conservado, aunque manchado en el lado derecho, color blanquecino, tinta marrón claro, tenor seguido, letras superpuestas en línea II salvadas al final.

El protocolo se inicia con una invocación muy corriente en el siglo $\mathrm{X}^{3}$, «Innomine domini»; le sigue la intitulación compuesta por el vocablo ego, los nombres de los cuatro otorgantes, y la indica-

1 Este análisis documental se llevó a cabo en la introducción inédita de mi tesis de doctorado, leída en octubre de 1983: El linaje de Castellvell en los siglos XI y XII (UAB, Bellaterra 1983).

2 En el sentido que le otorga R. MARICHAL, "La critique des textes», $L$ ' histoire et ses méthodes, Samaran-Gallimard, Bruges 1961, y A. DE BớARD, Manuel de diplomatique française et pontificale. I/ L'acte privé. Auguste Picard, Paris 1948. $2^{\circ}$ ed.: A. Giry, Manuel de diplomatique, 2 vols., Paris 1925.

3 Aunque esta misma invocación se prolonga ampliamente en los siglos posteriores, es en este momento una de las más frecuentes. F. UDINA MARTORELL, El Archivo Condal de Barcelona en los s. IX y XI. Estudio crítico de sus fondos. CISC, Barcelona 1951, afirma que aparece en un $90 \%$ de los casos, p. 28. 
ción del concepto jurídico del documento vinditores, y finalmente se cierra con la exposición de la dirección o destinatario.

El texto carece de preámbulo, notificación y exposición, iniciándose directamente con la cláusula dispositiva que se ajusta a un formulario muy corriente ${ }^{4}$, consignándose la procedencia por aprisión, los límites y el precio en sueldos. Cierran el texto las cláusulas finales conminatorias.

El protocolo final o escatocolo carece, como es natural, de data tópica, se compone de la datación y de los signos de validación. La fecha viene expresada por los años del rey Luis: «v idus novembris anno III regnante Leudovigo rege», lo cual motivó su clasificación, en las carpetas de Cancillería del Archivo de la Corona de Aragón, como un documento de la época de Ramón Berenguer III (Luis el Gordo), concretamente en 1110 . Sin embargo, como discutiré más adelante, al plantear su contenio, creo que debe entenderse Luis de Ultramar, a pesar de la ausencia de la filiación que suele acompañar la datación por este rey "filius Caroliw 5 .

Los signos de validación vienen constituidos por las firmas de los otorgantes, a las que precede la abreviatura de la palabra signum con la cruz inscrita en una circunferencia, con cuatro puntos en el caso de las dos primeras; junto a ellas se encuentran las firmas de los testigos, siete en total, las cuatro primeras con idéntico signum, cruz inscrita y puntos 6 . Aparece por último la firma del es-

4 Coincide con la estructura de la práctica totalidad de las ventas que se encuentran a lo largo del siglo $x$ en los fondos del ACA, veáse F. UDINA MARTORELl, El Archivo Condal...

5 Es decir, entre el 936 y el 954, que son los años de reinado de Luis de U1tramar, hijo de Carlos el Simple, y sucesor de Rodolfo. Véase A. CAPPELLI, Cronologia. Cronografia e Calendario Perpetuo, Manuali Hoepli, Milan 1930; véase también A. CAMPILlo MATHEU, Disquisitio methodi consignandi annos era Christiana, Barcelona 1766; G. FELIU Y MONTFORT «La cronología según los reyes francos en el condado de Barcelona s. X», Anuario de estudios medievales VI, 1969, pp. 441-464, J.A. MARAVAL L, «Sobre el sistema de datación por los reyes francos en los diplomas catalanes», Revista de Archivos, Bibliotecas y Museos LX, 1954, pp. 361, 374; y M. ZIMMERMANN, «La datation des documents catalans du IX au Xlle sieclen, Annales du Midi, 1976, pp. 345-375.

6 Son las firmas de los otorgantes Salomon, Vigilia, Stephano y Auriola. Aunque en alguna ocasión pueda encontrarse con posterioridad este tipo de firma, es 
criba Gregorius, que salva al final las letras superpuestas en el texto. Son autógrafas las firmas de Placidus, Geldericus y Ennego, acompañadas todas ellas de subscripciones con la triple $s$, como anagrama ${ }^{\top}$.

Como rasgos paleográficos más importantes hay que destacar la letra carolina; la $i$ inicial ocupa las dos primeras líneas; hay algunas letras de carácter arcaizante, como las $i$ altas de la segunda y tercera línea, la $n$ final de Salomon en la primera línea, las $q$ y las $g$ en general a lo largo del texto, y la abreviatura de pro expresada $f$.

Se puede señalar también la permanencia aún de la l en el topónimo Annolia.

\section{Segundo documento}

ACA, Cancillería, pergaminos Ramón Berenguer III núm. 253 (núm. 2). Venta de Sandred vicarius a su hijo Onofre Amat de tierras en el término de Castellvell, casa y viñas en la ciudadde Barcelona y en Sarrià, 31 de mayo de 951.

Pergamino de 150 × $395 \mathrm{~mm}$. Forma rectangular. Bien conservado, aunque algo roto en la parte superior izquierda, textura blanda, tinta marrón tirando a claro, letras superpuestas en línea II, IV, y X, salvadas al final.

El protocolo se inicia, como en el documento anterior, con la invocación «in nomine domini», y le sigue idéntica estructura: intitulación precedida de ego, indicación del concepto jurídico vinditor, y dirección.

El texto está ordenado de igual manera, sin preámbulo, notificación ni exposición, y con el dispositivo adecuado al mismo formulario, aunque se consigna la procedencia, en este caso por herencia y por compra. Así mismo cierran el texto las cláusulas conminatorias.

prototípica del siglo x y primeras décadas del XI. F. UDINA MARTOREL L la constata sobre todo en la segunda mitad del X: El Archivo Condal..., pp. 16

7 Este tipo de subscripción no se encuentra con posterioridad a las primeras décadas del siglo XI. 
En el protocolo final volvemos a encontrar, en cuanto a la datación, el mismo problema que señalábamos para el documento anterior: en este caso, la fecha expresada por los años del reinado del rey Luis es «II kalendas inuii anno XV regnante Lodovico rex», el documento se encuentra clasificado entre los del conde Ramón Berenguer III, es decir, fechado por los años de Luis el Gordo, concretamente en 1123; sin embargo, y aunque en este caso tampoco aparece la filiación del rey Luis, como sucedía en el documento anterior, creo que debe entenderse, por razones, entre otras, de contenido, como del rey Luis de Ultramar ${ }^{8}$. Los signos de validación están compuestos por la firma del otorgante y las sietede los testigos, entre las cuales las tres primeras van precedidas de la abreviatura de signum con la cruz inscrita en una circunferencia 9 ; cierra el documento la firma del escriba Salomon que salva al final las letras superpuestas en el texto. Son autógrafas las firmas de: Senderedus, Adimirus, Dunabile, Ato presbiter y la del escriba, varias de ellas acompañadas del subscripsit representado en el anagrama de tres $s^{10}$.

Rasgos paleográficos más característicos: letra carolina; la $i$ inicial ocupa cinco líneas; $g$ y $q$ arcaizantes; permanece la $l$ en el topónimo Annolia; palabras acabadas en $d$ y no en $t$, como por ejemplo pergid; y ausencia de $h$ en el ec de la firma del escriba: «Salomon qui ec scripsit...».

Tercer documento:

ACA, Cartulario de Sant Cugat, fol. 115 núm. 383 (núm. 3). El conde Borrell vende a Onofre, por sesenta monedas de oro,el cas-

8 Como sucedía en el documento anterior, éste está datado dentro de los primeros 18 años de los 28 que reinó Luis el Gordo, y en mi opinión hace referencia al período $936-954$

9 Galindo, Suzela y Usela, justamente aquéllas que no son autógrafas (excepto en los puntos) y que no van acompañadas de la subscripción con las tres s.

10 Senderedus: 多 ड़ईए Adimirus: Durabile: है? Ato presbiter:

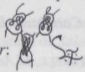

Argimirus:

Salomon:

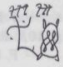


tillo de Sant Esteve de Castellet en la Marca, 11 de juniodel 977.

No voy a realizar aquí un análisis morfológico de este documento, puesto que pertenece al Cartulario de San Cugat ${ }^{11}$, pero sí de su estructura y contenido, para que nos sirva de referencia comparativa con los restantes.

$\mathrm{El}$ protocolo se inicia con una invocación algo diversa con respecto a los documentos anteriores, «in Dei nomine», pero, por lo demás, la estructura general del documento es similar a los comentados anteriormente; está fechado por los años del rey Lotario \&III idus iunii a. XXIII regnante Leuthario rege», y validado por la firma del otorgante, Borrell II, la de su esposa Letgarda, que da su consentimiento, trece firmas de testigos, y finalmente la del escriba Guillarane.

\section{Cuarto documento}

ACA, Cancillería, pergaminos Borrell II, núm. 15 (núm. 4). Cesión que hace Seniol a Guillem, su ahijado, hijo de Onofre Amat y Riquilda, de todas sus propiedades, que posee en diferentes lugares del condado de Barcelona por donación de su señor Onofre Amat ${ }^{12}$, 30 de enero del 978.

Pergamino de 105 x $287 \mathrm{~mm}$. Forma rectangular. Mal conservado y manchado, obscuro, recio y áspero. Tinta negro-pardusca. Tenor seguido.

Se encuentra una copia del siglo XI que facilita la lectura de este deteriorado documento en ACA, Borrell II, núm. 15 dupl.

Protocolo iniciado con la invocación «in nomine domini»; seguido de la intitulación, del concepto jurídico donator, y de la dirección que especifica la filiación materna y paterna del destinatario.

A diferencia de las ventas comentadas hasta ahora, el texto de esta donación se inicia con un preámbulo que recoge una fórmula corriente en el siglo $\mathrm{x}$. Seguidamente, la cláusula dispositiva con-

II J. Rius SerrA, Cartulario de San Cugat del Vallés. CSIC, Barcelona 1946, p. 101, doc. 126.

12 F. Udina Martorel., El Archivo Condal..., pp. 359-361, doc. 182. 
signa los límites y la procedencia por donación de su señor Onofre Amat. Se cierra el texto con las cláusulas conminatorias.

El escatocolo se compone de la fecha realizada por los años del reinado del rey Lotario: «III kalendas februarii anno XXIII regnante Leutario rege», y de los signos de validación: firma del otorgante, y cuatro firmas de testigos, una y otras precedidas de la abreviatura de signum, con la cruz inscrita en una circunferencia y con los cuatro puntos ${ }^{13}$; se cierra el documento con la firma muy borrosa del escriba, probablemente Salomone ${ }^{14}$.

La escritura es muy pequeña y difícil de tipificar por el estado del pergamino; $g$ semiunicales y $t$ unciales, $g$ uncial en la firma de Gualter; la $i$ inicial ocupa cuatro líneas.

\section{Quinto documento}

Archivo de la catedral de Barcelona, Diversorum C (a), documento núm. 32 (núm. 5). Venta de Ermentruit a Onofre Amat de una tierra en el castillo de Olèrdola, en el lugar de les Gunyoles, 19 de junio del 979.

Pergamino de $178 \times 272$ mm. Forma rectangular. Regular conservación, con numerosas manchas, sobre todo en el lado superior derecho, y dos agujeros. Tinta negra. Tenor seguido.

Comienza el protocolo con la invocación acostumbrada, «in nomine domini», la intitulación, y la dirección.

El texto no contienen más que el dispositivo, donde se especifica la procedencia de la propiedad por el diezmo esponsalicio, los límites de la misma, y el precio en sueldos; y las cláusulas finales conminatorias.

Finalmente, el escatocolo se compone de la fecha por los años del rey Lotario: «XIII kalendas iulii anno XXV regnante Leutario

13 Son las firmas del propio Seniullus, de Boveto, Gualter, Sunierfredus y Elias.

14 En el original puede leerse tan sólo la terminación mone, pero por la copia del siglo XI que lo acompaña sabemos que se trataba de Salomone, Borrell II, núm. 15, dupl. 
rexw y de los signos de validación: firmas de la otorgante y de siete testigos, todas ellas precedidas por la abreviatura de signum con cruz inscrita en circunferencia y cuatro puntos ${ }^{15}$; por último se encuentra la firma del escriba Wadamirus, con subscripción ${ }^{16}$.

Letra carolina; $i$ inicial ocupando cuatro líneas; carácter arcaizante de algunas $d \mathrm{y}$ de las $q$.

\section{Sexto documento}

ACB, Diversorum B, pergamino núm. 510 (núm. 6), Venta del Castellvell de la Marca de Calabuig y su hermano Guadamir a Sendred por 5.000 sueldos, 19 de abril (960-985?).

Este último documento, de los que incluimos en nuestro análisis, es un traslado realizado en 1196; por tanto, no llevaré a cabo un análisis morfológico sobre el mismo.

En este caso el protocolo, como en el documento núm. 3, comienza con la invocación «in Dei domine», tras la que siguen la intitulación y la dirección sin presentar variantes.

El texto, siguiendo la misma fórmula del resto de las ventas, carece de preámbulo, notificación y exposición, dividiéndose solamente en disposición y cláusulas conminatorias; en la disposición se especifica la procedencia por conmutación o permuta con el castillo de la Guàrdia, hecha por el conde Sunyer a los otorgantes, y se expresan detalladamente los límites del Castellvell de la Marca.

En la primera parte del escatocolo, la fecha, se nos presenta un problema que han señalado ya algunos historiadores 17 ; el documento dice textualmente: «XIII kalendas madii anno III regnante Karulus rex frater Leutarius». Las interpretaciones han sido diversas: al

is Son las firmas de la otorgante Ermetruite y de los testigos Livano, Ansarigo, Rodegado, Durando, Gondeberto, Guitardo, Gui.

16 Se trata de la subscripción con las tres $s$ :

17 M. ZIMMERMANN op. cit., p. 360.

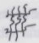


dorso del pergamino puede leerse la fecha de 19 de abril de 956 , atribuida por un archivista en la actualidad, llevado seguramente por la suposición de que debía contar por los años del rey Lotario, como si se tratase de un correinado con su hermano Carlos de Lorena; totalmente absurda me parece la fecha que le otorga la publicación de los índices de Caresmar referentes al siglo $\mathrm{X}$ en Scrinium $^{18}, 13$ de abril del 900 , que en este caso me parece absolutamente inexplicable; más lógica es la propuesta de $\mathbf{M}$. Zimmermann y J. Feliu Montfort, que consideran que se deben computar los años desde la muerte de Lotario, como si reinara Carlos de Lorena su hermano, que nunca llegó a ser rey, pero que tenía derecho a serlo. En este caso daría la fecha de 19 de abril del $990^{19}$; esta última datación, siendo como explicación aislada la más coherente, tiene la desventaja de la elevada edad que en ese caso tendrían tanto los otorgantes, que ya en el año 936 habían conmutado el castillo de la Guàrdia por el de Castellvell con el conde Sunyer, como del comprador, que, como hemos visto en el primer documento de este estudio, ya en el 938 compraba unos molinos en el Castellvell. Cotejando estos argumentos con otros de índole histórica, intentaré resolver la problemática de esta datación, como se verá más adelante.

La segunda parte del escatocolo, según figura en el traslado, son las firmas de los otorgantes precedidas del vocablo signum dividido entre la $g$ y la $n$ por la cruz con los cuatro puntos; le siguen siete firmas de testigos con idéntico signum, y la de Guadamir, segundo de los otorgantes y hermano del primero, que es además el escriba ${ }^{20}$.

Finalizan el documento la fórmula y fecha del traslado, 1196, las firmas de testigos y la del escriba de dicho traslado.

18 Edición de los índices de Caresmar; «Documentos del s. Xn, Scrinium VIIIIX, Barcelona 1953, p. 14, doc. 7. Caresmar le daba la fecha de 902; la publicación fecha 13 de abril del 900 .

19 Feliu MONTFORT, La cronología ..., p. 459; M. ZiMMERMAnN, La datación.... p. 360 .

20 Si las firmas han sido copiadas tal como estaban en el texto original, se encontrarían dentro de los pocos casos en el siglo $\mathrm{x}$ en el que aparece la cruz sin inscribirse en la circunferencia. 
La cuestión fundamental que la documentación estudiada plantea es la de la coherencia entre los datos expuestos y los contenidos. En el caso de los dos primeros documentos, cuyo principal problema reside en su clasificación entre la documentación de Ramón Berenguer UI (es decir, datados por los años del reinado de Luis el Gordo), podemos afirmar que la mayoría de sus características diplomáticas, paleográficas y de contenido abogan por una datación anterior, en el siglo $\mathrm{x} y$, por tanto, según los años del rey Luis de Ultramar. Los principales argumentos para afirmarlo son: los rasgos arcaizantes de algunas letras; las fórmulas diplomáticas; las firmas con cruz inscrita en circunferencia, y sobre todo aquellas que van acompañadas de subscripciones como las que he descrito anteriormente; la permanencia de la vocal líquida en el topónimo Annolia; la aparición del personaje de Onofre Amat, del que tenemos noticia por otros documentos del siglo $\mathrm{X}^{21}$, por los que sabemos además que fue padre de Guillem de Castellvell. Con respecto únicamente al documento núm. 2 , cabe añadir otros argumentos como la precisión de la frase que aparece al describir las afrontaciones de las propiedades vendidas: «...de meridie in via qui pergid ad ipsas torres de Mirone comite et de occiduo in ipsa solario vel in ipso casale qui fuid de condam Suniarii comiti... ${ }^{22}$. En mayo del 951 hace siete meses que el conde Sunyer ha muerto, y en cambio vive aún el conde Mir; por otro lado, las viñas de Bederrida (Sarrià) que vende Sendred a su hijo Onofre Amat en el mismo documento núm. 2 aparecen como propiedad de este último en el documento núm. 4 , 27 años más tarde, en el que Seniol, padrino de Guillem de Castellvell, tiene las viñas de Bederrida por su señor «Unifredo qui vocant Amadow ${ }^{23}$.

21 ACA, Borrell II, núm. 15: ACB, Div. C(a), nứm. 32; y también en el XI, una vez muerto, por los documentos de Guillem de Castellyell en los que se expresa la filiación: a...Guilielmo, filio qui fuisti Honofredi cognomi-nati Amati..., , ACA, Berenguer Ramón I, núm. 45 y a...Guilelmo, filio qui fuisti Amati...», Cartulario de Santes Creus, fol. $137 v^{\circ}$, ed, en F. UdINA MARTORELL, El Llibre Blanch de Santes Creus, pp. 9-10, doc. núm. 8.

22 Cf. apéndice doc núm. 2, ACA, Ramón Berenguer III, 253.

23 ACA, Borrell II, núm. 15, cf. apéndice 4. 
Por lo demás, los nombres de los otorgantes del documento núm. 1 y los de los testigos de ambos no ponen objeción, sino que más bien favorecen una datación alta:

\section{Documento núm. 1}

Salomon: a lo largo del siglo $\mathrm{x}$ encontramos este nombre en numerosas ocasiones y no lo volvemos a encontrar, en cambio, más allá de $1040^{24}$.

Vigilia: menos corriente, se haya, sin embargo, en algún otro documento en la época 25 .

Auriola: aparece con frecuencia en la documentación del siglo $\mathrm{x}$ bajo las formas de Aureolus y Auriolus, no volviendo a encontrarse a partir del siglo $\mathrm{XI}^{26}$.

Stephanus: aparece con frecuencia en el siglo $\mathrm{X}$, aunque también posteriormente 27 .

Bera: se encuentra una signatura con este nombre en un documento del ACA del año $904^{28}$, y no aparece posteriormente.

Altemiro: se encuentra con frecuencia a lo largo de todo el siglo $\mathrm{X}$ y las dos primeras décadas del $\mathrm{XI}^{29}$, no posteriormente.

Rusticus: no he encontrado este nombre en ningún otro documento.

Fructuosus; aparece en alguna ocasión más, en el siglo $\mathrm{X}^{30}$, no posteriormente.

24 Los documentos de fecha más cercana al comentado en los que aparece el nombre de Salomon son: Cart. S. Cugat. (citaré por el número de documento en la publicación) núm. 35 (954), 43 (956), 50 (957), y ACA, Mirón 54 núm. 83 de la publicación (927), Seniofredo 13, núm. 101 (931), Seniofredo 34 núm. 123 (947), Seniofredo 38 núm. 127 (949). El número citado junto a la signatura del ACA es el de la publicación.

25 ACA, Borrell II 2, núm. 168 (968).

26 Cartulario S. Cugat, núm. 41 (955), 46 (956), 68 (963) y ACA Seniofredo 4, núm. 93 (929), Seniofredo 12 núm. 100 (931), Seniofredo núm. 15, núm. 103 (932), Seniofredo 16 núm. 104 (932).

27 Aunque disminuye notablemente a partir de aproximadamente 1075.

28 ACA, Wifredo I 13, núm. 16.

29 Cart. S. Cugat núm. 42 (955), 43 (956), 57 (959), 58 (959)... y en ACA, Seniofredo 15 núm. 103 (932), Seniofredo 16 núm. 104 (932) y Seniofredo 66 núm. 153 (961), entre otros.

30 Cart. S. Cugat núm. 10 (921) y 121 (977). 
Placidus presbiter: el nombre de Plácido se encuentra en algún documento del siglo $\mathrm{X}$, aunque no como presbiter $^{31}$. No lo he localizado posteriormente.

Geldericus: bajo la forma de Gellericus he localizado una firma en el ACA, año 97432.

Ennego: nombre frecuente en todo el siglo $\mathrm{X}^{33}$, en ocasiones se encuentra en el siglo XI, pero es menos corriente ${ }^{34}$.

\section{Documento núm. 2}

Galindo qui vocant Mothone: aparece numerosas veces, en el siglo X y primera mitad del XI, el nombre de Galindo, pero nunca acompañado del de Mothone.

Suzela: aparece entre los testigos de dos documentos del 961 y 971, respectivamente ${ }^{35}$, y en dos más fechados en 100436; no lo he vuelto a localizar con posterioridad a esta fecha.

Usela: lo he encontrado en una sola ocasión, y bajo la forma de Uxela, en un documento del 96437.

Adimirus: no muy frecuente, pero localizable en el siglo $\mathrm{X}^{38}$, no posteriormente.

Argimirus: corriente en el siglo $\mathrm{x}$ y primera mitad del $\mathrm{xI}^{39}$.

31 ACA, Mirón 3 núm. 38 (913) y Borrell II 14 núm. 181 (977).

32 ACA, Borrell II 9, núm. 175 (974).

33 Cart. S. Cugat, núm. 31 (949), 45 (956), 47 (956), 49 (957), 60 (959) y ACA, Mirón 3 núm. 38 (913), Mirón 51 núm. 87, Seniofredo 13 núm. 101 (931), Seniofredo 32, núm, 121 (942) Seniofredo 33, núm. 123 (947), Seniofredo 56 (959), núm. 145...

34 Cart. S. Cugat, núm. 371 (1002), 395 (1004), 509 (1028), 520 (1031) y, por última vez, en 1086 núm. 726 bajo la forma de Enneg Isarn.

35 Cart. S. Cugat, núm. 63 (961) y 96 (971).

36 Cart. S. Cugat, núm. 390 (1004) y 391 (1004).

37 ACA. Seniofredo 74, núm. 163 (964).

38 ACA, Mirón 3 núm. 38 (9³); y Cart. S. Cugat, núm. 27 (947), 71 (964), y 108 (975).

${ }^{39}$ Cart. S. Cugat, núm. 27 (947), 46 (956), 104 (974) (los más cercanos a la fecha del documento comentado); y en ACA, Mirón 52 núm. 88 (928). Seniofredo 15 núm. 103 (932), Seniofredo 23 núm. 112 (938), Seniofredo 29 núm. 118 (942), Seniofredo 35 núm. 124 (948), Seniofredo 58 núm. 147 (960). 
Durabile: común a lo largo del siglo X, no posteriormente 40 .

Ato presbiter: el nombre de Ato aparece con frecuencia en el siglo X, concretamente como presbiter en el 904 y $910^{41}$, en el 942 , y en el $955^{42}$.

Sin embargo, algunos rasgos de ambos documentos dificultan la solución definitiva de su datación. En primer lugar, la mencionada datación por los años del rey Luis sin añadir la filiación (filius $\mathrm{Ca}$ roli), corriente en los documentos de Luis de Ultramar. En el Archivo de la Corona de Aragón no existe ningún documento de este rey, clasificado en las carpetas del siglo $\mathrm{X}$, en que no aparezca dicha filiación. Lo mismo sucede en el Cartulario de San Cugat, según la ordenación cronológica de la edición de J. Rius Serra ${ }^{43}$. Tanto es así, que se ha afirmado que en la diferenciación de los documentos fechados por reyes que recibieron el nombre de Luis, los de Luis de Ultramar son quizá los de más fácil identificación ${ }^{44}$. Sin embargo, en otros archivos, como por ejemplo en el de la Catedral de Vic, o en el capitular de Urgell, he podido comprobar que, a pesar de que en la mayoría de los documentos de este rey aparece efectivamente la filiación, se encuentran otros, con relativa frecuencia, fechados exclusivamente por el reinado del rey Luis sin inidación alguna 45 . Ello reduce la dificultad de datación de los documentos comentados, y nos lleva a una posible explicación de su clasificación entre las carpetas de Ramón Berenguer III, ya que, tal vez, aquellos documentos de los 18 años de reinado de Luis de Ultramar en los que no figura el indicativo de filiación fueron clasificados en su día en-

40 Cercanos a la fecha del doc, 951: Cart. S. Cugat, núm. 10 (921), y 97 (972). En el último cuarto de siglo aparece en frecuentes ocasiones. ACA, Seniofredo I, núm. 90 , Borrell II 14, núm. 181 (977).

41 Cart. S. Cugat, núm. 2 (904) y 4 (910).

42 ACA, Seniofredo 32 núm. 121 (942) y Seniofredo 43 núm. 132 (955).

43 J. Rius SERRA, El cartulario de San Cugat...; véanse documentos de este reinado.

44 F. Udina Martorell, El Archivo Condal.... pp. 79.

45 Véase, por ejemplo, A.C. de Vic, calaix 6, doc. 1565, «V kalendas december anno II regnante Leudovico regen, ed. en JUNYENT I SUBIRA, Diplomatari de la Catedral de Vic s. IX.X. v. 2, doc. 175, p. 149, o calaix 6 núm. 220 ж...anno regnante Leudivicho regen, ed. ídem pp. 150-51, doc. 177; o calaix 6, núm. 1246, «anno VI regnante Loloico rege», ed. idem doc. 197, pp. 168-169, etc. 
tre los de los 18 primeros años del de Luis el Gordo; lo mismo habría sucedido con la ordenación cronológica del Cartulario de San Cugat, pues, como el propio J. Rius Serra afirma en su introducción, el criterio de diferenciación seguido para identificar a los Luises es precisamente la filiación en el caso de Luis de Ultramar ${ }^{46}$, Ligado a este problema se encuentra justamente la principal objeción que se le podría poner al documento núm. 1 de los comentados: la aparición como escriba de Gregorius, nombre desconocido en la documentación catalana de los siglos X y XI, pero que en cambio aparece también como escriba en una donación testamentaria a la abadía de Sant Cugat fechada por J. Rius Serra en 1116: «...anno VIII regnante Leodovigo rege ${ }^{47}$. Es evidente que si este documento estuviera bien datado, sería un argumento importante a favor de la clasificación del otro documento también en el siglo XII, pues entonces sí existiría un escriba que recibiera ese extraño nombre para la época; debo añadir que un Gregorio y el otro son con toda probabilidad el mismo escriba, dado que, habiendo consultado la copia de su firma en el propio Cartulario de San Cugat, fol. 228, ésta resulta ser idéntica a la del documento 134 de Ramón Berenguer $\mathrm{m}^{48}$, pero los nombres y el contenido de este nuevo documento vuelven a estar de acuerdo, como sucedía en los dos anteriores, con el contexto general del siglo $\mathrm{X}^{49}$. Por todo ello, debo volver sobre mi argumentación anterior e insistir en la errónea clasificación de algunos documentos de Luis de Ultramar en los 18 primeros años de Luis el Gordo, añadiendo que es únicamente en esos primeros 18 años, que

46 Cart. S. Cugat, p. XIV.

${ }^{47}$ Cart. S. Cugat, t. III, p. 32, núm. 831 (fol. 228 núm. 715).

48 Por supuesto, la del Cartulario es la copia de la firma de Gregorius, pero se pueden distinguir perfectamente sus rasgos:

$$
3 \text { Gregorius levita qui... et }
$$

49 De nuevo, como ocurría en los documentos 1 y 2 , todos los nombres que aparecen en éste pertenecen con exclusividad o con preferencia al siglo X: Baftefredus, Oliba, Galindus, Flavius, Luppo, Albaro, Ranemirus, Lodisclo; además, al describir las afrontaciones se lee «... de circi in terra de Suniario comite...». Aun en el caso de que se diera por supuesto que está muerto, es extraña su aparición como propietario de una tierra 166 años después de su muerte. 

tran documentos de carácter arcaizante ${ }^{50}$.

50 Sin pretender profundizar en este tema, ni dar una lista exhaustiva de documentos que considero erróneamente clasificados, he podido observar anomalías en varios pertenecientes a los 18 primeros años, y sólo a los 18 primeros, del reinado de Luis el Gordo, algunos de los cuales, publicados en la edición del Cartulario de San Cugat, me interesa destacar aquí por los personajes que en ellos aparecen y su repercusión en el tema que estoy tratando: t. III, pp. 36-37 doc. núm. 836 (fol. 162 , doc, 527) figura la fecha «...anno viu regnante Ludovico rege», llama la atención la ausencia de un solo nombre compuesto, y el carácter arcaizante de los que aparecen: Eldebaldus, Oliolus, Ermenaldus, Bonefilius, Spanla, y Durandus, firma por último el escriba Cinibertus; se encuentran muchas d en la terminación de las palabras, y el vocablo Annulis conseva la consonante líquida. T. III p. 57, doc. 859 (fol. 345 , núm. 1010) fecha *...anno XIIII regnante Leudovico rege*, ausencia de nombres compuestos y carácter arcaizante de los simples: Seniuldus, Sunieredus presbiter, Calepodius prebiter, Vuitiza presbiter, firma finalmente el escribano Ennego levita, única vez que aparece Enego en el siglo XII en todo el cartulario, mientras que se localiza un Ennego escriba entre los años 973-983. T. III, p. 64, doc. 867 (fol 319, doc. 1066) fecha «... anno XV regnante Leudovico rege», ausencia de nombres compuestos simples arcaizantes: Vuiliara, Amanrisclus, Dachus, Inquilbertus, Adaulfus, y Truitarius; firma el escriba Suniefredus presbiter, lo cual no es muy indicativo, pues encontramos un Seniofred presbítero y escriba durante la segunda mitad del $\mathrm{x}$ pero también en el xI, el último documento de este escriba, sin contar el que comento, que data de 1089 . T. III, pp. 66-67, doc. 871 (fol. 225vo núm. 705) fecha kanno XVI regnante Lodeicus reso, ausencia de nombres compuestos, simples arcaizantes: Suniarius, Susanna Adila, Sesegoncia, Auriolo presbiter Ella, Achila, Todino; cierra el documento la firma del escriba Auriols presbiter, quien se atestigua como tal presbítero y escribano entre los años 953 y 978 , no conociéndose ningún otro documento aparte del comentado de este escriba en el siglo XII. T. III, pp. 77.78 núm. 884 (fol. 374 núm. 1082), fecha *,..,anno XVIII regnante Ludovico regen, ausencia de nombres compuestos, simples arcaizantes: Orila, Ranlo, Gontardus, Matrona, Segamirus, Wisandus Calepodius presbiter, firma el escriba Suniarius levita; en el siglo x existe un Suniarius escriba, pero no se consigna que sea levita. Además, a lo largo del XI también encontramos documentos con un escriba de ese nombre; sin embargo, la última vez que se encuentra, sin contar el documento que comento, es en 1064, en el propio cartulario. Finalmente, t. III, pp. 79.80 doc. 887 (fol. 368 núm. 1064), fecha «...anno XViII regnante Lodovico reges; ausencia de nombres compuestos, simples arcaizantes: Rudirigo, Ranimirus, Ermenilde, Anna, Onorada, Dacus, Wisandus, Ermemirus, Ermenisclus; firma Atto presbiter, de quien no tenemos ningún otro testimonio en el siglo XII, y aparece en cambio como testigo en numerosos documentos del x y, si se puede identificar con el Ato levita que aparece en el mismo siglo, se atestiguaría también como escriba. 
Ante este panorama, creo que lo que no puede ponerse en duda es que los documentos 1 y 2 hacen referencia a acontecimientos y personajes del siglo X, y que deben fecharse por el reinado de Luis de Ultramar. Se podría objetar, en cambio, la relativa perfección de la letra, salvando los rasgos arcaizantes, sobre todo en el caso del doc. núm. 2, donde la escritura se acerca a los caracteres de la letra de códice. Ello podría explicarse incluso adecuándose a las fechas expresadas (938 y 951) si los escribas provinieran de medios monásticos, al menos el del segundo documento, Salomón, hipótesis que queda desde luego por demostrar. Finalmente, cabría preguntarse acerca de la originalidad y autenticidad de ambos documentos: respecto a la primera, la posibilidad de que se tratase de una copia coetánea o posterior; abogan en su contra la abundancia de firmas originales existentes en los dos documentos. Respecto a la segunda, creo que viene suficientemente apoyada tanto por la exactitud de los datos que el texto aporta, como, por ejemplo, la muerte del conde Suñer, como, de nuevo, por la abundancia de subscripciones ológrafas, y el hecho de salvar correctamente las letras superpuestas; en cualquier caso, no existen motivos serios para ponerla en duda.

Los documentos núms. 3, 4 y 5 no plantean, ni en sus caracteres formales ni en sus contenidos, ningún problema de especial relevancia, lo cual los faculta para clarificar los anteriormente citados. Hay que señalar en concreto, respecto al documento núm. 4 , la borrosa firma del escriba, que parece que se puede transcribir, tal como indica la copia, por Salomonesi y, en ese caso, podría tratarse del mismo que aparece en el documento núm. 2. Sin embargo, y a pesar del mal estado del documento, legible en su totalidad sólo por la copia, no parece ser la misma letra.

Queda por exponer la problemática que plantea el documento núm. 6 al introducirse en el contexto general del siglo $x$, cuestión que se agrava al tratarse de un traslado, donde se pierden muchas posibilidades de confirmación, y disminuye lógicamene la fiabili-

51 Tal como he expuesto antes, lo único que puede distinguirse en la firma es la terminaicón mone, pero la copia del siglo XI nos confirma el nombre de Salomone. 
dad del documento. El problema se refiere fundamentalmente a la fecha; las soluciones que se han adoptado ante ella las he expuesto más arriba, y debo reconocer que la más lógica a simple vista es la aportada por J. Feliu Montfort y Zimermann ${ }^{52}$, interpretando que se trata de Carlos de Lorena. Pero si comparamos el documento con el resto de la información que tenemos acerca de sus personajes a lo largo del siglo $\mathrm{X}$, observamos:

1) Que los otorgantes de la venta, Calabuig y Guadamir, permutaban el castillo con el conde Suñer en el año 936, el que se dice además que eran «satélites» ${ }^{53}$; si aceptamos, por tanto, la fecha de 990 para la venta, tendrían ambos más de 70 años, edad considerablemente alta para su época.

2) Que del mismo modo el comprador, Sendred, con toda probabilidad el padre de Onofre Amat, que en el año 938 compraba unos molinos ${ }^{54}$, tendría sobre $\operatorname{los} 70$ años.

3) Que la compra la efectuaría Sendred en vida de su hijo Onofre, y en vida de su nieto Guillem de Castellvell, sin que uno u otro aparezcan ni en el texto ni como testigos.

Ciertamente, ninguno de estos tres argumentos es definitivo, pero hacen que resulte extraña una datación tan tardía. A ello podemos añadir que Eneg "que vocant Bonefilio», personaje relevante en la documentación de la segunda mitad del siglo $\mathrm{X}$, era con mucha probabilidad hijo del Sendred que estamos tratando, dado su parentesco con Onofre y con Guillem de Castellvell ${ }^{55}$; en ese caso, en febrero del 990 (como muy tarde), Sendred habría muerto, como se expresa en un documento del Cartulario de San

52 La Cronología..., p. 459; La datation des documents catalans..., p. 360.

53 Tenemos conocimiento de esta permuta por una reparatio realizada en el año 1027 por Guillem I de Castellvell: ACA, Berenguer Ramón I, núm. 56 cf. apéndice núm. 12.

54 El documento núm. 1 del apéndice es la venta de los molinos a Sendered; en el núm. 2 efectúa una venta él mismo a su hijo Onofre Amat.

55 Su parentesco con Guillem de Castellvell, que intentaré perfilar con más claridad en la primera parte de esta tesis es, prácticamente seguro, fraterno, pero no se puede afirmar con absoluta certeza; por ello, el argumento que expongo no es definitivo para confirmar el error de datación del documento comentado. 
Cugat: «...ego Ennego que vocant Bonefilio, filium quondam Sendredi... ${ }^{56}$, con anterioridad, pues, a la fecha de abril del 990.

En esta ocasión el análisis de la onomástica que aparece en el texto, comparada a la de la época, no nos es de gran ayuda, pues, en lo que respecta a los otorgantes, el nombre de Calabuig es extremadamente raro: lo encontramos únicamente mencionado en la reparatio que, de la permuta (936) del Castellvell con el Castillo de la Guàrdia, hiciera Guillem de Castellvell en 102757, y en dos ocasiones entre los testigos de dos documentos fechados por J. Rius Serra en 1122 y 1125 pero que, tal como he intentado desmostrar antes, creo que deben situarse en el 950 y 953 , respectivamente ${ }^{58}$. Por su parte, el nombre del otro otorgante, Guadamir, que es además el escriba, es excesivamente frecuente incluso como presbiter, pudiendo encontrarse a lo largo de todo el siglo $\mathrm{x}$. El desconocimiento de su signatura, por tratarse de un traslado, nos impide analizarlo comparativamente 5 . Por otro lado, si se tratase del mismo Guadamirus presbiter que firma como escriba en las dos últimas décadas del siglo X, sería muy extraño que, en esta ocasión, hubiera datado el documento por el supuesto reinado de Carlos de Lorena, toda vez que en octubre del 987 fechaba un documento «....ano IIII regnante $U$ go, reges 60 . Por su parte, las signaturas de los testigos tampoco aportan, en esta ocasión, ningún dato revelador: Aspidio y Gridelle no aparecen en otros documentos, Rechosen aparece a lo largo de todo el siglo $\mathrm{x}$ y primeras décadas del XI con mucha frecuencia ${ }^{61}$, lo mismo

56 Cart. S. Cugat, fol. 367, núm. 1060, ed. J. Rius Serra, pp. 204-205 núm. 243.

57 ACA, Berenguer Ramón I, núm. 56.

58 Véase nota 107.

59 Dado que el traslado ni siquiera imita la firma o las posibles rúbricas y anagramas del original. Entre las diversas escrituras en que figura un escriba Guadamir presbítero se encuentra la núm. 5 de nuestro apéndice.

60 Cart. S. Cugat, fol. 2, núm. 48, ed. J. Rius Serra, t. 1, p. 220 núm. 261 e fd. fol. 344, num. 985, ed. id. t. 1, pp. 75-76, nüm. 210.

61 Este nombre lo encontramos en el ACA por primera vez en los esponsalicios del conde Suñer, Cancillería, Pergaminos Suñer, extrainventario 1 (898-917), pero lo seguimos encontrando a lo largo del siglo $x$ en numerosas ocasiones, y menos corrientemente en el XI, donde también se encuentra. 
sucede con Stephanus ${ }^{62}$, y, aunque en menos ocasiones, con Savarig63, el nombre de Galavonso aparece mencionado en un documento del 923 bajo la forma de Galavanso, sin que podamos afirmar con seguridad que se trate de la misma persona ${ }^{64}$, aunque, si así fuera, sería un argumento para una datación anterior; el nombre de Morgad, por su parte, aparece en un documento del $915^{65}$, para no reaparecer hasta el 1002 , entre los testigos de un documento del Cartulario de San Cugat 66 .

Llaman la atención, también, en este documento, la exactitud y amplitud de las anfrontaciones descritas, sin duda las más precisas que se encuentran para el Castellvell de la Marca, y que coinciden en líneas generales con las de la venta realizada en 1023 por los condes Berenguer Ramón I y Sancha a Guillem de Castellvell, del mismo castillo ${ }^{67}$, aunque en esta ocasión son mucho más escuetas.

Ciertamente, ante estas perspectivas no es mucho lo que se puede afirmar con absoluta seguridad; motivos de orden histórico ${ }^{68}$, me inclinan a poner en duda la resolución dada por J. Feliu y Montfort y M. Zimermann a esta extraña fecha: ¿error del original?, ¿error del traslado?, ¿puede el traslado haber sido hecho sobre una copia fechada en el 990?, y aun aceptando que el traslado fuera del original, y éste estuviera fechado en el 990, ¿podría la venta real haber tenido lugar, tal vez, con anterioridad a la redacción de un acta jurídica? Las respuestas a tales preguntas dificílmente podrían ser demostradas sean cuales fueren, pero la cotejación del proceso segui-

62 Stephanus es muy corriente en el $x, y$ en el xı hasta aproximadamente el aก̃o 1075 .

63 ACA, Mirón 40, núm. 76 (923). Seniofredo 14, núm. 102 (932), Borrell II. 13 núm. 180 (976), Borrell II 14 núm. 181 (977); Cart. St. Cugat 328 (997), 509 (1028),...

64 ACA, Mirón 41, ed. núm. 77.

65 ACA, Mirón 12, ed. núm. 47.

66 Fol. 143, núm. 463, ed. J. Rius Serra, t. II, pp. 33-34, doc. núm. 383.

67 F. UdinA MARTORELL, El Llibre Blanch de Santes Creus CISC, Barcelona 1947. pp. 9-10, doc. núm. 8.

68 Para un planteamiento general de la problemática histórica remito al primer capítulo de mi tesis de doctorado, «La formación: la organización del territorio*. 
do por los Castellvell, en la organización territorial del Penedès, y el de los restantes linajes, me inclinan a ofrecer la dudosa, pero más verosímil fecha, para la adquisión del Castellvell de la Marca de Sendred entre el 960 y el 985. 